Article

\title{
Development of a Recombination System for the Generation of Occlusion Positive Genetically Modified Anticarsia Gemmatalis Multiple Nucleopolyhedrovirus
}

\author{
Santiago Haase ${ }^{1}$, Christina B. McCarthy ${ }^{1,2}$, M. Leticia Ferrelli ${ }^{1}$, Matias L. Pidre ${ }^{1}$,
} Alicia Sciocco-Cap ${ }^{3}$ and Victor Romanowski ${ }^{1, *}$

1 Instituto de Biotecnología y Biología Molecular (IBBM), Departamento de Ciencias Biológicas, Facultad de Ciencias Exactas, Universidad Nacional de La Plata, CONICET, 1900-La Plata, Argentina; E-Mails: shaase@biol.unlp.edu.ar (S.H.); cmccarthy@conicet.gov.ar (C.B.M.); 1ferrelli@biol.unlp.edu.ar (M.L.F.); mlpidre@biol.unlp.edu.ar (M.L.P.)

2 Centro Regional de Estudios Genómicos (CREG), Facultad de Ciencias Exactas, Universidad Nacional de La Plata, 1900-La Platae, Argentina

3 Instituto de Microbiología y Zoología Agrícola (IMYZA), Instituto Nacional de Tecnología Agropecuaria (INTA), 1712-Castelar, Argentina;

E-Mail: sciocco.alicia@inta.gob.ar

* Author to whom correspondence should be addressed; E-Mail: victor@biol.unlp.edu.ar; Tel./Fax: +54-221-422-9777.

Academic Editor: John Burand

Received: 14 January 2015 / Accepted: 26 March 2015 / Published: 31 March 2015

\begin{abstract}
Anticarsia gemmatalis is an important pest in legume crops in South America and it has been successfully controlled using Anticarsia gemmatalis Multiple Nucleopolyhedrovirus (AgMNPV) in subtropical climate zones. Nevertheless, in temperate climates its speed of kill is too slow. Taking this into account, genetic modification of AgMNPV could lead to improvements of its biopesticidal properties. Here we report the generation of a two-component system that allows the production of recombinant AgMNPV. This system is based on a parental AgMNPV in which the polyhedrin gene (polh) was replaced by a bacterial $\beta$-galactosidase (lacZ) gene flanked by two target sites for the homing endonuclease I-PpoI. Co-transfection of insect cells with linearized (I-PpoI-digested) parental genome and a transfer vector allowed the restitution of $p o l h$ and the expression of a heterologous gene upon homologous recombination, with a low background of non-recombinant AgMNPV. The system was validated by constructing a recombinant occlusion-positive (polh ${ }^{+}$) AgMNPV
\end{abstract}


expressing the green fluorescent protein gene $(g f p)$. This recombinant virus infected larvae normally per os and led to the expression of GFP in cell culture as well as in A. gemmatalis larvae. These results demonstrate that the system is an efficient method for the generation of recombinant AgMNPV expressing heterologous genes, which can be used for manifold purposes, including biotechnological and pharmaceutical applications and the production of orally infectious recombinants with improved biopesticidal properties.

Keywords: AgMNPV; recombinant baculovirus; bioinsecticide; Anticarsia gemmatalis; velvetbean caterpillar

\section{Introduction}

Baculoviruses are double-stranded, circular DNA viruses that have drawn wide attention not only for their use as vectors for the expression of recombinant proteins in insect cells, but also for their potential use as biological control agents [1]. During virus replication, virions are included in large protein crystals called occlusion bodies that allow the virus to remain viable for many years in the environment, outside the insect host until another host ingests them. The velvetbean caterpillar, Anticarsia gemmatalis Hübner (Lepidoptera: Noctuidae) is considered one of the main foliage feeding pests of legume crops in South America, affecting mainly soybean fields. Anticarsia gemmatalis multiple nucleopolyhedrovirus (AgMNPV) belongs to the Alphabaculovirus genus of the Baculoviridae family and is used as a biological agent to control this pest, being the most widely used viral bioinsecticide worldwide [2-4].

However, a number of problems currently prevent the widespread use of this virus. A major drawback is that AgMNPV is relatively slow in killing its host insect in temperate climates. Depending on the age and susceptibility of the host, the virus may take up to two weeks to kill the insect. During that period, the insect can continue to feed. One approach to improve the speed of kill of baculoviruses is the introduction of foreign, insecticidal genes into the viral genome $[5,6]$. In order to facilitate the recovery of recombinant viruses expressing non-reporter genes, and to reduce the time required for recombinant virus cloning, the proportion of parental viruses in the progeny obtained after the co-transfection should ideally be suppressed. Several strategies have been developed for other baculoviruses (reviewed in [7]). One of the more exploited strategies to generate genetically modified baculoviruses relies on the homologous recombination mechanism. However, the frequency of recombination is low, and typically only $0.1 \%-2 \%$ of progeny viruses are recombinant. If linearized viral DNA, which cannot initiate a viral infection unless rescued by a recombination event, is used instead of circular wild type DNA, the proportion of recombinant progeny can be increased to about 30\% [8]. Moreover, it was demonstrated that the incorporation of two endonuclease recognition sites in AcMNPV, was more effective in reducing the parental virus background progeny than the incorporation of a single unique site [9]. In this work we report the development of a system for the generation of AgMNPV recombinants consisting of two components: a parental occlusion negative baculovirus DNA engineered to contain the E. coli lacZ ORF flanked by two unique intron-encoded endonuclease sites used to linearize the viral DNA, and a transfer vector containing the polyhedrin (polh) gene and a heterologous gene of choice. After co-transfection of the linearized viral parental DNA with the transfer vector and recombination, the loss of the lacZ gene 
and the recovery of the polyhedrin gene are clear indicators that the recombinant virus has been generated.

\section{Materials and Methods}

\subsection{Virus, Cells and Insects}

AgMNPV-2D isolate (wild type) [10] was used as the parental virus for the generation of AgMNPV-I-PpoI. UFLAg-286 (kindly supplied by Dr. Bergmann Ribeiro; Universidade de Brasília) and High-FiveTM (BTI-TN-5B1-4, Invitrogen ${ }^{\mathrm{TM}}$, Carlsbad, CA, USA) cells were grown at $28{ }^{\circ} \mathrm{C}$ in TC-100 or Grace's (Invitrogen ${ }^{\mathrm{TM}}$ ) media containing 10\% fetal bovine serum (Internegocios S.A., Mercedes, Argentina). A. gemmatalis were reared at IMYZA, (INTA, Castelar, Argentina). Larvae were maintained in the laboratory on an artificial diet [11] under controlled temperature $\left(26 \pm 1{ }^{\circ} \mathrm{C}\right)$, photoperiod (14L/10D) and 80\% relative humidity.

\subsection{Recombinant DNA Methods}

The construction of vectors was performed according to standard molecular cloning procedures [12]. All constructs were confirmed by restriction analysis and sequencing. Oligonucleotide primers used in the study are indicated in Tables 1 and 2 (see also Figure S1).

Table 1. Primers used to generate the transfer vectors $\mathrm{pAg}-\mathrm{IPpoI}$ and $\mathrm{pI}$. Relevant restriction sites incorporated in the primers are underlined and the nucleotides that anneal with the template are highlighted in bold.

\begin{tabular}{|c|c|}
\hline Primer name & Primer sequence \\
\hline Upr10-NdeI & GCCCATATGCACAGTCAACGCCGGCC \\
\hline Lpr10-SgfI & GCCCGCGATCGCGACGATATTGAAATGGTTGAAATAAATATAC \\
\hline Uprom-NdeI & GCCCСАTATGAAGTTGCAGCTCAAGCAGGATTGT \\
\hline Ppolhrev-NotI & CATTGCGGCCGCAATTCAAGCTTAGTTATAGCAAATTTTACTAC \\
\hline Uup-RsrII & CCCCGGTCCGATGACCGAATTGAGCAACGCG \\
\hline Lup-SfiI & CTAGTTGGCCGCCTCGGCCTGCTGACTAAGCGTAGACC \\
\hline Lred-SfiI & CGCTTAGTGGCCGAGGCGGCCAACTAGAATGCAGTGAAAAAAATG \\
\hline $\mathrm{SV} 40 / \mathrm{CcdB}-\underline{\mathrm{XmaI}}$ & ATGGACCACCCCGGGTTCCTGTAGCGGCCGCG \\
\hline Polhi-SgfI & AAATTTGCGATCGCTATGCCAGATTATACG \\
\hline Ldw- $\underline{\mathrm{Bg} I I I}$ & GGAAAGATCTATACACACGTTAGGCGAGCGCCG \\
\hline eGFP/Up-EcoRI & TCCATCGAATTCATGGTGAGCAAGGGC \\
\hline eGFP/Dw-XhoI & CTGATAAGCTTCTCGAGTCGCGGCCG \\
\hline
\end{tabular}


Table 2. Primers used for the characterization of cloned AgMNPV-GFP. The nucleotides that anneal with the template are highlighted in bold. Relevant restriction sites incorporated in the primers are underlined.

\begin{tabular}{cc}
\hline Primer name & Primer sequence \\
\hline Polhi- $\underline{\text { SgfI }}$ & AAATTTGCGATCGCTATGCCAGATTATACG \\
AgDwrec & AACCCGTAAAGCCGCCGTTG \\
AgUpsrec & GGCGCGAGTTAAATAGTCTG \\
SV40/CcdB- $\underline{\text { XmaI }}$ & ATGGACCACCCCGGGTTCCTGTAGCGGCCGCG \\
LacZ & TGGATCTGCAACATGTCCCAGGTGA \\
ppolhAg600UphindII & TGTACAAAGCTTCTAATTGCGTAAAAATG \\
pie1Agfw & TATAAGATCTCAGGGTACAATTG \\
pie1Agrev & CATGAAGATCTATTTATACC \\
\hline
\end{tabular}

\subsection{Construction of the AgMNPV-I-PpoI Recombinant}

Transfer vector pAg-I-PpoI was constructed as described by McCarthy and Romanowski [13] (Figure 1). Briefly, linkers containing the I-PpoI recognition sequence (CTCTCTTAA'GGTAGC) were introduced flanking the $l a c Z$ gene in pAgPHZ [14]. AgMNPV-2D DNA was then co-transfected with pAg-IPpoI in UFLAg-286 cells using Tfx-20 (Promega, Fitchburg, WI, USA) (Figure 1). Recombinant AgMNPV-I-PpoI was isolated by five successive rounds of plaque purification and a simplified method for the extraction of baculoviral DNA for PCR analysis was employed to test the viruses each step [15]. Finally, the AgMNPV-I-PpoI was amplified and its genomic DNA was purified from cell culture supernatant according to standard protocols [16]. The identity of the recombinant virus was confirmed by PCR, restriction analysis and Southern blot hybridization (Figure 1). I-PpoI digestion conditions were previously optimized in our laboratory in order to achieve complete digestion of the recognition sequence embedded in different contexts [13].

\subsection{Transfection of Linearized AgMNPV-I-PpoI DNA vs. Circular Undigested Genome}

UFLAg-286 cells were transfected with linearized and undigested AgMNPV-I-PpoI DNAs using TfX-20 ${ }^{\mathrm{TM}}$ (Promega, Fitchburg, WI, USA), according to the manufacturer's protocol $(500 \mathrm{ng} / 35 \mathrm{~mm}$ dish). I-PpoI digestion conditions were optimized as descripted previously [13]. Five days after transfection, the cell culture supernatant was replaced with $3.5 \mathrm{~mL}$ Grace's medium containing 10\% fetal bovine serum (Internegocios S.A., Mercedes, Buenos Aires, Argentina) and $120 \mu \mathrm{g} / \mathrm{mL}$ X-Gal

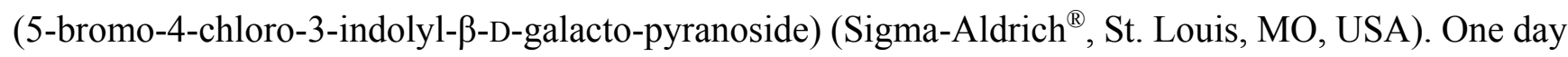
later, cells were washed twice with phosphate buffered saline (PBS) and harvested in $1 \mathrm{~mL}$ lysis buffer (0.25\% SDS, $10 \mathrm{mM}$ Tris- $\mathrm{HCl} \mathrm{pH}$ 7.6). Cell lysates were clarified by centrifugation at $1000 \times g$ for $10 \mathrm{~min}$ and $50 \mu \mathrm{L}$ of supernatant was measured in a spectrometer (spectra were recorded for the 400-700 nm wavelength range). Relative enzyme activity was measured as units of absorbance at $650 \mathrm{~nm}$ - the maximum absorbance wavelength for blue-colored X-Gal hydrolysis product (colorless galactose plus 5-bromo-4-chloro-3-hydroxyindole, which spontaneously dimerizes and is oxidized into 5,5'-dibromo-4,4'-dichloro-indigo). 


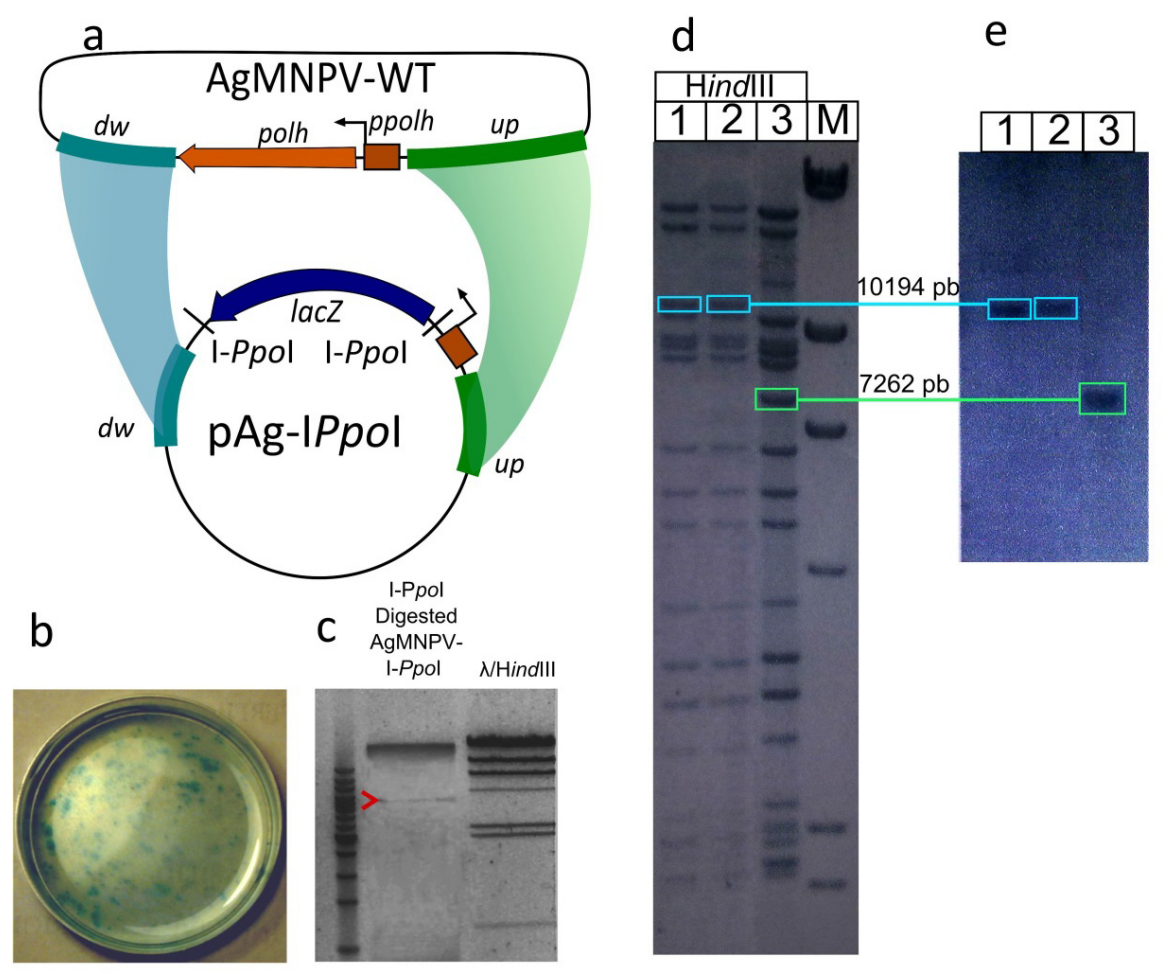

Figure 1. Generation of the parental genome AgMNPV-I-PpoI. (a) Homologous recombination between AgMNPV-2D and pAgIPpoI substitutes the lacZ ORF for the polyhedrin ORF and provides two I-PpoI restriction sites. The sequences flanking the polh gene are indicated as up (upstream: $829 \mathrm{bp}$ ) and $d w$ (downstream: $883 \mathrm{bp}$ ); (b) Cell culture dish infected with AgMNPV-I-PpoI showing lacZ $\beta$-galactosidase-positive plaques; (c) AgMNPV-I-PpoI digested with I-PpoI: release of a $3 \mathrm{~kb}$ fragment (see arrowhead) containing the lacZ ORF flanked by I-PpoI restriction sites; (d) HindIII restriction patterns of genomic DNA from two AgMNPV-I-PpoI clones (lanes 1,2) and wt AgMNPV (lane 3). The HindIII G bands are highlighted with boxes; (e) Southern blot using a probe targeting downstream polh sequences in band G with $(10,194 \mathrm{bp}$; lanes 1,2) or without (7262 bp) the lacZ ORF (lane 3).

\subsection{Generation of the Transfer Vector pI3}

Transfer vector pI3 was constructed by sequential ligation of fragments from the AgMNPV-2D genome and fragments derived from commercial vectors (Figure S1). The primers used for the generation of the plasmid are listed in Table 1. In the first stage, a fragment containing the promoters of the 10 and polyhedrin (polh) genes in opposite orientation was constructed following a combination of PCR amplifications, restriction digestions and ligations, as described in the following lines. The p10 promoter was amplified with primers Upr10-NdeI and ligated in pGEM-T-Easy vector (generating pGEM-T-pp10). The polh promoter was amplified with primers Uprom-NdeI and pPolhrev-NotI. The polh promoter PCR product and the pGEM-T-pp10 vector were digested with NdeI and Pst I (PstI site present in pGEM-T-Easy vector) and ligated in the NheI and PstI sites from, pGEM-T-pp10, generating pGEM-T-pp10-ppolh. The upstream region of the polyhedrin gene was amplified by PCR; the SV40 polyadenylation signal was added by Splice Overlap Extension (SOE) PCR and ligated in the 
RsrII/NotI digested pIRES plasmid (Clontech), generating the pIRES-UpspA vector. The primers used to amplify the upstream region were Uup-Rsr and Lup-Sfi, and the SV40 polyA was amplified from the commercial vector pDsRed1-N1 (Clontech) with primers Lred-Sfi and SV40/CcdB-XmaI. The fragment containing the $p 10$ promoter and the polh promoter in a back-to-back orientation was first released from pGEM-T-p10-ppolh by digestion with NotI and then ligated in the same restriction site of pIRESUpspA, yielding the pIRES-UpspA-pp10-ppolh vector. Finally, the polh ORF sequence with the polh gene downstream region was amplified from the AgMNPV-2D genome with primers Polhi-Sgfl and Ldw-BglII and ligated in pIRES-UpspA-pp10-ppolh Sgfl and $B g l I I$ recognition sites, generating transfer vector pI3 (Figure S1).

\subsection{Construction of Recombinant AgMNPV-GFP}

Enhanced GFP ORF was amplified by PCR from the commercial vector peGFP-N3 (Clontech) with primers eGFP/Up-EcoRI and eGFP/Down-XhoI, and cloned in pGEM-T-Easy (Invitrogen) following the manufacturer's recommendations. The plasmid pI3-GFP was then constructed by releasing the GFP ORF from pGEM-T-GFP by digestion with EcoRI and subsequently ligating it into EcoRI-digested and dephosphorylated pI3.

In order to generate AgMNPV-GFP, High Five ${ }^{\mathrm{TM}}$ cells were co-transfected with $2 \mu \mathrm{g}$ of linearized parental AgMNPV-I-PpoI viral DNA and $2 \mu \mathrm{g}$ of pI3-GFP using Cellfectin II $^{\mathrm{TM}}$ (Invitrogen ${ }^{\mathrm{TM}}$ ), according to the manufacturer's recommendations (Figures 2 and 3 ).
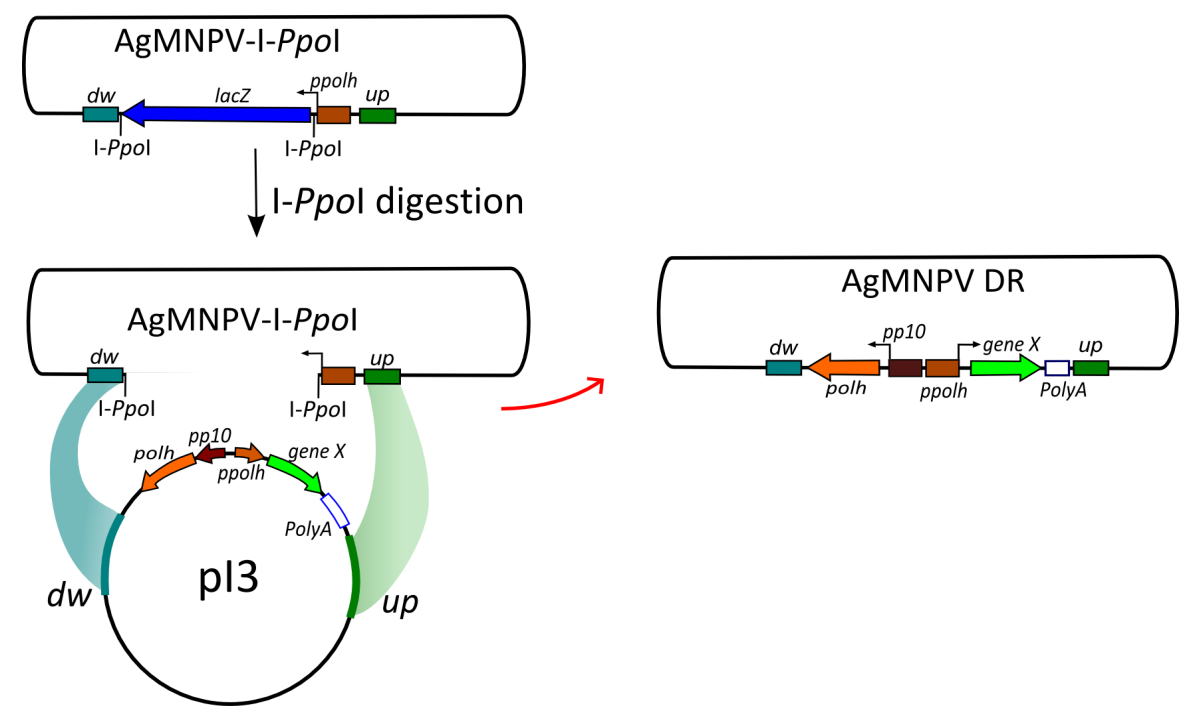

Figure 2. Schematic representation of the recombination system. Parental genome (AgMNPV-I-PpoI) is linearized by digestion with I-PpoI, and co-transfected with the transfer vector (pI3). Homologous recombination restores genome viability (re-circularization) generating recombinant progeny. Sequences flanking the original polh gene, where recombination can occur, are indicated as $d w$ (511 bp downstream polh ORF stop codon; AgMNPV genome nucleotide positions 132,239-131,729) and up (610 bp upstream the polh promoter; AgMNPV genome nucleotides positions 934-1543). See [4] for AgMNPV genome nucleotide numbers. 


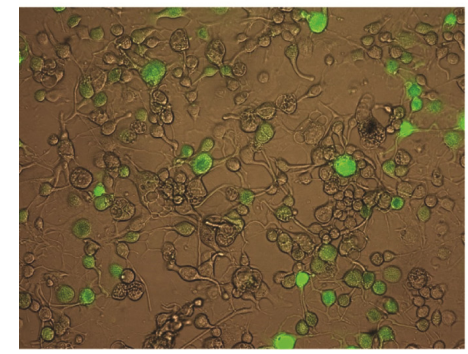

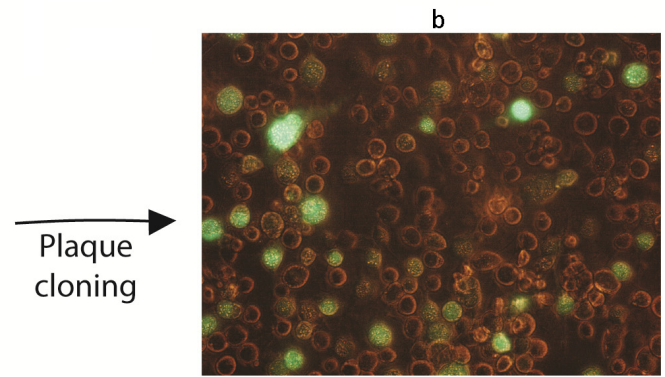

Figure 3. Generation of AgMNPV-GFP. (a) GFP (green fluorescent protein) expression in High Five ${ }^{\mathrm{TM}}$ cells co-transfected with linearized AgMNPV-I-PpoI and pI3-GFP (schematic in Figure 4a); (b) High Five ${ }^{\mathrm{TM}}$ cells infected with cloned AgMNPV-GFP. Cells were infected with recombinant virus recovered from the plug of the agarose overlay from a single selected plaque. The differences in the levels of GFP expression of individual cells are related to the low multiplicity of infection.
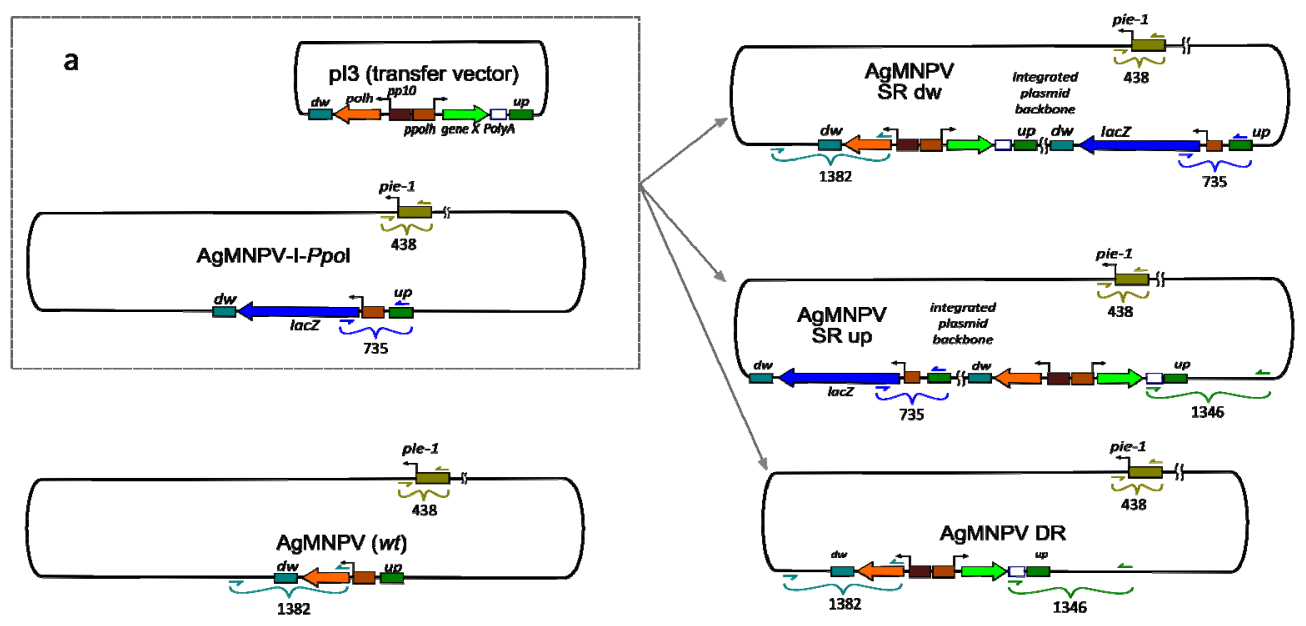

b
\begin{tabular}{|c|c|c|c|c|c|}
\hline PCR & $\begin{array}{c}\text { AgMNPV } \\
(\text { Wf }\end{array}$ & $\begin{array}{c}\text { AgMNPV } \\
\text { l-Ppo-1 }\end{array}$ & $\begin{array}{c}\text { AgMNPV } \\
\text { SR } \\
\text { up }\end{array}$ & $\begin{array}{c}\text { AgMNPV } \\
\text { SR } \\
\text { dw }\end{array}$ & $\begin{array}{c}\text { AgMNPV } \\
\text { DR }\end{array}$ \\
\hline pie-1 & 438 & 438 & 438 & 438 & 438 \\
\hline lacZ & - & 735 & 735 & 735 & - \\
\hline$d w$ & 1382 & - & - & 1382 & 1382 \\
\hline up & - & - & 1346 & - & 1346 \\
\hline
\end{tabular}

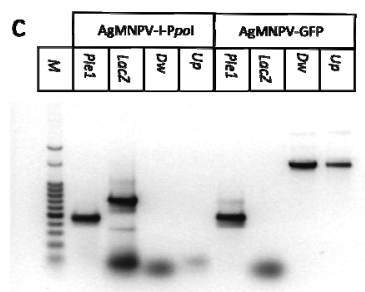

Figure 4. Characterization of cloned AgMNPV-GFP. (a) Schematic representation of plasmid (pI3-gene X) and viral DNA (AgMNPV-I-PpoI) used in the study and possible viral genomic recombination products in plasmid-genome cotransfections. Genomes that could arise from uncut AgMNPV-I-PpoI DNA are also included (SR: Single Recombinant; DR: Double Recombinant; $d w$ and $u p$ : downstream and upstream polh ORF sequences where recombination could occur) Positions of PCR primers are indicated. A scheme of a wt AgMNPV is also included in order to clarify the origin of the putative PCR products that are shown in the table. (b) Table presenting the sizes of expected PCR amplicons in each possible genomic product (primers are those listed in Table 2); (c) Agarose gel electrophoretic patterns of PCR products using cloned AgMNPV-GFP (DR) and AgMNPV-I-PpoI DNAs as templates. 
When occlusion bodies and GFP fluorescence became apparent in the transfected cells, the supernatant was collected and used to infect High Five ${ }^{\mathrm{TM}}$ cell monolayers for subsequent plaque purification [17]. Occlusion-positive/GFP-positive plaques were selected and purified through three successive rounds of plaque isolation.

\subsection{Characterization of AgMNPV-GFP}

AgMNPV-GFP was amplified in High Five ${ }^{\mathrm{TM}}$ cells and the infected cell monolayers were observed by fluorescence microscopy (Nikon Eclipse Ti, Tokyo, Japan). AgMNPV-GFP and AgMNPV-I-PpoI genomic DNA were purified from cell culture supernatants according to standard protocols [17]. The primers used for the characterization of the AgMNPV-GFP recombinant are listed in Table 2. The primers polhi-Sgfl and AgDwrec were used to detect a recombination in the polh downstream sequence; to detect recombination in the polh upstream region, the primers were AgUpsrec and SV40/CcdB-XmaI; and to detect the lacZ ORF in parental undigested DNA and simple homologous recombinants, the primers used were LacZ and ppolhAg600UpHindIII. The upstream and downstream primers anneal to AgMNPV sequences flanking the recombination region but not to transfer plasmid sequences. Consequently, an amplification fragment of the expected size is observed only when homologous recombination has taken place. A PCR amplification product of the iel gene promoter was used as a positive control for AgMNPV DNA template, using primers pie1Agfw and pie1Agrev.

\subsection{Per os Infection of A. gemmatalis Larvae with Recombinant AgMNPV}

AgMNPV-GFP and AgMNPV-wt polyhedra were generated in High Five ${ }^{\mathrm{TM}}$ cells and purified according to standard protocols [16]. Polyhedra suspensions were prepared in sterile distilled water containing 1\%(v/v) Coomassie brilliant blue (Sigma-Aldrich ${ }^{\circledR}$, St. Louis, MO, USA) and sucrose $\left(\right.$ Sigma-Aldrich $\left.{ }^{\circledR}\right)$. A. gemmatalis 3rd instar larvae were fed with this preparation using a modified droplet feeding method [18]. Larvae were infected with 2000 OB/larva (approximately 10 LD50), taking into account the previously reported mean volume ingested by A. gemmatalis 3rd instar larvae [19] and $\mathrm{LD}_{50}$ data for larvae from this same instar [20]. Infected larvae were evidenced by the presence of fluorescence when whole organisms were exposed to UV light. After five days post-infection, larvae were dissected and hemolymph cells and tracheoles were observed using fluorescence microscopy (Nikon Eclipse Ti).

\section{Results}

\subsection{Construction of a Linearizable AgMNPV Genome}

In order to simplify the isolation of genetically modified AgMNPVs, a homologous recombination system for AgMNPV based on the linearization of the parental genome was developed (Figure 1). The parental genome, designated AgMNPV-I-PpoI, was generated by homologous recombination between AgMNPV-2D (referred to as wt, Zanotto et al. 1992) and pAg-I-PpoI (lac $Z^{+}$) transfer vector after co-transfection of an insect cell culture (see Materials and Methods). Virus plaques with a lac $Z^{+}$ polh-phenotype were identified (Figure 2b) and isolated. In AgMNPV-I-PpoI the polyhedrin ORF was 
replaced with the E. coli $\beta$-galactosidase ORF (lacZ) flanked by two sites of recognition for the intron-encoded endonuclease I-PpoI, which enable the linearization of the genome.

AgMNPV-I-PpoI DNA was characterized by restriction analysis and Southern blot (Figure 2). AgMNPV-wt and AgMNPV-I-PpoI HindIII restriction patterns were differentiated by a change in the $\mathrm{G}$ band, from 7262 bp in AgMNPV-wt to 10,194 bp in AgMNPV-I-PpoI. Also, after digesting AgMNPV-I-PpoI with I-PpoI, a $3 \mathrm{~kb}$ fragment (containing the lacZ ORF) was detected (Figure 2).

\subsection{Transfection of Insect Cells with Circular vs. Linear AgMNPV Genomic DNA}

In order to demonstrate the efficacy of the linearization of AgMNPV-I-PpoI DNA in reducing parental genome viability, LacZ expression was assessed in cell monolayers transfected in parallel with circular and I-PpoI-digested viral DNA. As described in Materials and Methods, the relative enzyme activity was estimated by measuring the hydrolysis of X-Gal: a decrease of $c a$. 40-fold in hydrolyzed $\mathrm{X}-\mathrm{Gal}$, was observed in cells transfected with linearized parental genome when compared with non-digested genomic DNA (data not shown), indicating that linearization was not $100 \%$ complete, but significantly lowered the amount of parental infectious virus recovered in the transfection.

\subsection{Construction of a Transfer Vector for the Generation of Occlusion-Positive Recombinant AgMNPV}

The transfer vector pI3 was constructed in order to introduce genetic modifications in the polh locus of AgMNPV. The salient features are two strong AgMNPV promoters (polh and p10) placed back to back. This cassette is flanked by upstream and downstream sequences surrounding the polh ORF in the AgMNPV genome (details can be found in Section 2.5 and supplementary file). Since the final aim was to produce recombinant AgMNPVs orally infectious ( polh $^{+}$) to A. gemmatalis larvae, pI3 was designed to contain the polh ORF (preceded by p10 5'-untranslated sequence) under the control of the $p 10$ promoter and followed by the polh downstream region, including the transcriptional termination signal. Three unique restriction sites placed after the polh promoter can be used to clone the ORF of choice, followed by the SV40 polyadenylation-termination signal and the polh upstream region (Figure 2). The transfer plasmid pI3-GFP was constructed by ligating gfp ORF in pI3 previously digested with EcoRI (Section 2.6).

High Five ${ }^{\mathrm{TM}}$ cells were cotransfected with pI3 and linearized (digested) or circular (undigested) AgMNPV-I-PpoI. Supernatants of these transfections were used to infect High Five ${ }^{\mathrm{TM}}$ monolayers in varying dilutions and the proportions of white (recombinant) and blue (parental) plaques was evaluated using standard protocols with chromogenic $\beta$-galactosidase substrate X-Gal. Transfection using circular parental genomic DNA yielded more than $99 \%$ of blue and less than $1 \%$ white plaques. In contrast, when digested AgMNPV-I-PpoI DNA was cotransfected with pI3, 90\% of the observed plaques were white and only $10 \%$ were blue (data not shown).

\subsection{Co-Transfection of Viral DNA and Transfer Plasmid}

After the generation of the parental genome (AgMNPV-I-PpoI), a recombinant AgMNPV carrying the $g f p$ gene under the control of the polyhedrin promoter was generated in order to validate the 
recombination system (Figure 3). AgMNPV-GFP was produced by homologous recombination between linearized AgMNPV-I-PpoI and the transfer vector pI3-GFP. The virus was cloned by three rounds of plaque purification. A cell monolayer was infected with cloned AgMNPV-GFP, and GFP expression and production of occlusion bodies were verified (Figure 3).

The viral DNA was characterized by PCR using the sets of primers mentioned in Materials and Methods (Table 2). The results indicate that the AgMNPV-GFP clone analyzed was derived from double homologous recombination between AgMNPV-I-PpoI and pI3-GFP (Figure 4). In this process, lacZ was replaced with a cassette containing polh and $g f p$ genes under the control of very late baculoviral promoters.

\subsection{The Recombinant AgMNPV-GFP Infects Cells Producing Polyhedra, which Are Orally Infective to A. gemmatalis Larvae}

After assessing the genetic organization of plaque-cloned AgMNPV-GFP and observing its ability to express both GFP and polyhedrin and to generate occlusion bodies in insect cell culture (Figure 3b), infectivity via oral route was evaluated on A. gemmatalis larvae (Figure 5). No differences in insecticidal parameters were evidenced when compared with wild type virus (Figure 5). GFP expression in whole animal and in secondary tissues of larvae infected with AgMNPV-GFP was observed (Figure 5), demonstrating the dispersion of the infection in the larvae.


Figure 5. A. gemmatalis larvae orally infected with AgMNPV-GFP OBs (red arrowheads) and wt AgMNPV OBs (blue arrowheads) exposed to visible light (a) and UV light (b); tracheolar (c) and hemolymph (d) cells extracted from A. gemmatalis larvae infected with AgMNPV-GFP OBs. In the inset panel, polyhedra inside the nucleus of an infected cell are highlighted. (e) Results of mean time to death and mortality of $A$. gemmatalis larvae infected with recombinant AgMNPV-GFP and wt AgMNPV ( $n=20$ per treatment). The larvae consumed $50\left(1 \mathrm{LD}_{50}\right)$ and $300 \mathrm{OBs}\left(6 \mathrm{LD}_{50}\right)$ in parallel experiments. 


\section{Discussion}

A limited number of recombinant AgMNPV have been reported and used to study the biology of this virus or to improve its biopesticidal parameters [14,21-24]. Recently, the generation of an occlusion-positive $\left(\right.$ pol $\left.^{+}\right)$recombinant AgMNPV carrying CfDefNPV v-cath (cathepsin) and chiA (chitinase A) genes was reported [21]. This recombinant AgMNPV showed an improved insecticidal activity against $A$. gemmatalis larvae when compared with AgMNPV-2D. However, owing to the lack of an efficient recombination system, the isolation of the recombinant virus demanded seven isolation cycles. On the other hand, the genetic characterization of this recombinant AgMNPV does not allow distinguishing if it is the result of double or simple homologous recombination. Considering that it takes about 10 days to complete one round of plaque isolation, the generation of recombinant viruses requires at least three months. In this regard, it has been previously reported that serial passages of recombinant baculoviruses in cell culture must be minimized because they may lead to the accumulation of defective viruses that can become the predominant species produced [25]. This is of special importance when a recombinant virus is to be tested as bioinsecticide, since the accumulation of mutations in genes related to oral infectivity does not affect virus propagation in cell culture. Furthermore, since the simultaneous manipulation of multiple recombinant baculovirus is not recommended because of the risk of cross-contamination, the time required for genetically modified baculovirus cloning limits the number of alternative recombinants that can be obtained.

As mentioned previously, the classical way of making recombinant viruses is based on homologous recombination between the viral genome and a transfer plasmid in insect cells, where the frequency of recombination is low, and only $0.1 \%-2 \%$ of progeny viruses are recombinant. In this respect, earlier reports showed that linearization of the baculovirus DNA at a single unique site increased the proportion of recombinant viruses to about 30\% [8], whereas the incorporation of two unique restriction sites resulted in recombination frequencies of over 90\% [9]. Given that linearized viral DNA was much less infectious than the circular form, this resulted in a great reduction in the background of non-recombinant viruses, but a relatively small reduction in the yield of recombinant viruses was observed [9]. Furthermore, the high proportion of recombinants following transfection with linear viral DNA was due to a reduction in the background of parental viruses, rather than to an increase in the absolute number of recombinants obtained. However, the presence of a small proportion of uncut viral-parental DNA cannot be completely ruled out and might be the source of unwanted non-recombinant progeny and might also yield single cross-over recombinants (SR genomes in Figure 4) and aberrant non-homologous recombination products. In our hands, a single round of isolated plaque purification is sufficient to assure a pure clone of rAgMNPV, e.g., AgMNPV-polh ${ }^{+} g f p^{+}$. Two additional plaque purification rounds were done to completely rule out the carryover of contaminant genotypes.

Initial experiments were conducted using UFLAg-286 cells, which are highly efficient for AgMNPV replication; however, culture and lipid-mediated transfection of High Five ${ }^{\mathrm{TM}}$ cells turned out to be easier in our hands without seriously compromising virus yields. Therefore, this cell line is currently used in our lab for genetic modifications of AgMNPV.

In summary, a versatile recombination system for the efficient genetic modification of AgMNPV was developed and tested. This two-component system is based on the linearization of a parental baculovirus DNA and a transfer vector containing the polyhedrin gene and a heterologous gene of choice (both under 
the control of very late viral strong promoters). Our results prove that the recombination system described here significantly reduces the amount of time required for clonal purification of genetically modified AgMNPV. To validate the procedure, a recombinant AgMNPV harboring the $g f p$ gene was produced; this virus efficiently infected $A$. gemmatalis larvae by oral route and expressed the heterologous gene at high levels.

Pest control using wt AgMNPV has been very successful in Brazil in the past 30 years, but failed in more temperate climates because of the relatively slow speed of kill of the virus in these conditions. The two-component system described here will facilitate the generation of AgMNPV recombinants, including heterologous genes designed to improve its bioinsecticidal capacity or to address other aspects of fundamental or applied baculovirus molecular biology.

\section{Acknowledgments}

This work was supported by grants from the Agencia Nacional de Promoción Científica y Tecnológica (ANPCyT, Argentina) and Universidad Nacional de La Plata (UNLP) to VR and ASC and the Instituto Nacional de Tecnología Agropecuaria (INTA) to ASC. VR and CBMcC hold research career awards from CONICET (Consejo Nacional de Investigaciones Científicas y Técnicas, Argentina). ASC is a staff researcher at IMYZA-INTA (Instituto de Microbiología y Zoología Agrícola, Instituto Nacional de Tecnología Agropecuaria, Argentina). SH and MLP are a recipients of research fellowships from CONICET, and MLF is a postdoctoral fellow of ANPCyT.

\section{Author Contributions}

Santiago Haase constructed the transfer plasmid pI3, obtained the recombinant AgMNPV-GFP, conducted the bioassays and wrote the manuscript. Christina B. McCarthy generated the parental virus AgMNPV-I-PpoI, conducted the $\beta$-galactosidase activity assay, obtained and purified the viral DNA and revised the manuscript. María Leticia Ferrelli and Matías L. Pidre collaborated with the bioassays, the design of oligonucleotides sequences and revised the manuscript. Alicia Sciocco-Cap is one of the senior scientists in the project; she established the insect rearing facility, provided the equipment for virus and DNA purification, advised on the study and revised the manuscript. Victor Romanowski conceived the study, supervised the experiments and revised the manuscript. All authors approved the final manuscript.

\section{Conflicts of Interest}

The authors declare no conflict of interest.

\section{References}

1. Szewczyk, B.; Hoyos-Carvajal, L.; Paluszek, M.; Skrzecz, I.; Lobo de Souza, M. Baculoviruses-Re-emerging biopesticides. Biotechnol. Adv. 2006, 24, 143-160.

2. Allen, G.E.; Knell, J.D. A nuclear polyhedrosis virus of Anticarsia gemmatalis: I. Ultrastructure, replication and pathogenicity. Fla. Entomol. 1977, 60, 233-240. 
3. Moscardi, F. Assessment of the application of baculoviruses for control of Lepidoptera. Annu. Rev. Entomol. 1999, 44, 257-289.

4. Oliveira, J.V.; Wolff, J.L.; Garcia-Maruniak, A.; Ribeiro, B.M.; de Castro, M.E.; de Souza, M.L.; Moscardi, F.; Maruniak, J.E.; Zanotto, P.M. Genome of the most widely used viral biopesticide: Anticarsia gemmatalis multiple nucleopolyhedrovirus. J. Gen. Virol. 2006, 87, 3233-3250.

5. Bonning, B.C.; Hammock, B.D. Development of recombinant baculoviruses for insect control. Annu. Rev. Entomol. 1996, 41,191-210.

6. Maeda, S. Increased insecticidal effect by a recombinant baculovirus carrying a synthetic diuretic hormone gene. Biochem. Biophys. Res. Commun. 1989, 165, 1177-1183.

7. Haase, S.; Ferrelli, M.L.; Pidre, M.L.; Romanowski, V. Genetic Engineering of Baculoviruses. In Current Issues in Molecular Virology-Viral Genetics and Biotechnological Applications; Romanowski, V., Ed.; InTech: Rijeka, Croatia, 2013; doi:10.5772/56976.

8. Kitts, P.A.; Ayres, M.D.; Possee, R.D. Linearization of baculovirus DNA enhances the recovery of recombinant virus expression vectors. Nucleic Acids Res. 1990, 18, 5667-5672.

9. Kitts, P.A.; Possee, R.D. A method for producing recombinant baculovirus expression vectors at high frequency. BioTechniques 1993, 14, 810-817.

10. Zanotto, P.M.; Sampaio, M.J.; Johnson, D.W.; Rocha, T.L.; Maruniak, J.E. The Anticarsia gemmatalis nuclear polyhedrosis virus polyhedrin gene region: Sequence analysis, gene product and structural comparisons. J. Gen. Virol. 1992, 73, 1049-1056.

11. Hoffmann-Campo, C.B.; de Oliveira, E.B.; Moscardi, F. Criação Massal da Lagarta da Soja Anticarsia gemmatalis; Documentos 10; EMBRAPA-CNPSo: Londrina, Brazil, 1985; p. 23.

12. Sambrook, J.; Fritsch, E.F.; Maniatis, T. Molecular Cloning: A Laboratory Manual, 2nd ed.; Cold Spring Harbor Laboratory Press: Cold Spring Harbor, NY, USA, 1989.

13. McCarthy, C.B.; Romanowski, V. Digestion of I-PpoI recognition sites in unfavorable sequence contexts achieved by changing the reaction conditions. Biochem. Genet. 2006, 44, 61-68.

14. Arana, E.I.; Albariño, C.G.; O’Reilly, D.; Ghiringhelli, P.D.; Romanowski, V. Generation of a recombinant Anticarsia gemmatalis multicapsid nucleopolyhedrovirus expressing a foreign gene under the control of a very late promoter. Virus Genes 2001, 22, 363-372.

15. McCarthy, C.B.; Romanowski, V. A simplified method for the extraction of baculoviral DNA for PCR analysis: A practical application. J. Virol. Methods 2008, 148, 286-290.

16. O'Reilly, D.R.; Miller, L.K.; Luckow, V.A. Baculovirus Expression Vectors: A Laboratory Manual; Oxford University Press: New York, NY, USA, 1994.

17. Murhammer, D.W. Baculovirus and Insect Cell Expression Protocols. Methods Mol. Biol. 2007, 388, 1-404.

18. Hughes, P.R.; Wood, H.A. A synchronous peroral technique for the bioassay of insect viruses. J. Invertebr. Pathol. 1981, 37, 154-159.

19. Kunimi, Y.; Fuxa, J.R. Volumes ingested by four species of noctuids with reference to peroral droplet bioassay of baculoviruses. J. Invertebr. Pathol. 1996, 68, 310-311.

20. Abot, A.R.; Moscardi, F.; Fuxa, J.R.; Sosa-Gómez, D.R.; Richter, A.R. Development of Resistance by Anticarsia gemmatalis from Brazil and the United States to a Nuclear Polyhedrosis Virus under Laboratory Selection Pressure. Biol. Control 1996, 7, 126-130. 
21. Lima, A.A.; Aragao, C.W.; de Castro, M.E.; Oliveira, J.V.; Sosa-Gómez, D.R.; Ribeiro, B.M. A Recombinant Anticarsia gemmatalis MNPV Harboring chiA and v-cath genes from Choristoneura fumiferana defective NPV induce host liquefaction and increased insecticidal activity. PLoS ONE 2013, 8, e74592, doi:10.1371/journal.pone.0074592.

22. Pinedo, F.J.R.; Moscardi, F.; Luque, T.; Olszewski, J.A.; Ribeiro, B.M. Inactivation of the ecdysteroid UDP-glucosyltransferase (egt) gene of Anticarsia gemmatalis nucleopolyhedrovirus (AgMNPV) improves its virulence towards its insect host. Biol. Control 2003, 27, 336-344.

23. Ribeiro, B.M.; Gatti, C.D.; Costa, M.H.; Moscardi, F.; Maruniak, J.E.; Possee, R.D.; Zanotto, P.M. Construction of a recombinant Anticarsia gemmatalis nucleopolyhedrovirus (AgMNPV-2D) harbouring the beta-galactosidase gene. Arch. Virol. 2001, 146, 1355-1367.

24. Soares, J.S.; Ribeiro, B.M. Pathology of Anticarsia gemmatalis larvae infected by two recombinant A. gemmatalis multicapsid nucleopolyhedroviruses. Res. Microbiol. 2005, 156, 263-269.

25. Pijlman, G.P.; van den Born, E.; Martens, D.E.; Vlak, J.M. Autographa californica baculoviruses with large genomic deletions are rapidly generated in infected insect cells. Virology 2001, 283, $132-138$.

(C) 2015 by the authors; licensee MDPI, Basel, Switzerland. This article is an open access article distributed under the terms and conditions of the Creative Commons Attribution license (http://creativecommons.org/licenses/by/4.0/). 